\title{
Neurological examination of patients suffering from leprosy: is it worthwhile?
}

\author{
F G I JENNEKENS* \& A JENNEKENS-SCHINKEL $\dagger$ \\ *Division of Neuromuscular Diseases, University Hospital, PO Box \\ 85500,3508 GA Utrecht, The Netherlands; $\dagger$ Department of Neuro- \\ psychology, University Hospital Leiden, The Netherlands
}

Accepted for publication 28 February 1992

\begin{abstract}
Summary We examined 28 male leprosy patients to discover if a more extensive neurological investigation than usual would be worthwhile in diagnosis and/or management. Our findings were fully compatible with what might be expected from a mononeuritis multiplex, either due to leprosy or other causes. The following observations are noteworthy. Changes of position sense and a decrease of some tendon reflexes were present in a minority of the patients. In soles of the feet, considered to be an- or hypaesthetic, some residual pain sensation could occasionally be detected. Functional testing of at least one muscle group ( $\mathrm{m}$. triceps surae) appeared to be more reliable than manual testing according to MRC criteria. We concluded that an extensive neurological examination is probably not required for diagnosis. It does provide, however, more accurate information on the extent of damage to the peripheral nervous system, which may be important for management and for assessment of treatment effects. The use of a myometer is advocated.
\end{abstract}

\section{Introduction}

Leprosy is predominantly, though not exclusively, a disease of nerves and skin, and therefore it would seem logical to submit patients (suspected of) suffering from leprosy to a full neurological examination. In current practice, however, examination is restricted to selected aspects of neurological functioning, as is clear from handbook literature $\mathrm{e}^{1-3}$ and as we observed during a visit to the two main leprosy hospitals of Nepal in May 1991. In these hospitals, pressure sensation was carefully tested during so-called body charting, either using the ballpoint method or Semmes-Weinstein filaments, ${ }^{4}$ and weakness of skeletal muscles was examined either by simple functional tests or manually. Peripheral nerves were palpated to assess whether they were enlarged, and the skin was examined for dryness and fissuring as indicators of loss of sweating. Pain sensation was examined when indicated. Other parts of the neurological examination for peripheral neuropathies were, however, disregarded. Tendon reflexes were not elicited, and vibration sense, position sense and co-ordination were not examined. 
It is not clear why the most common neurological methods of examination are not employed, as these are neither difficult nor time consuming. With a little training, they could easily be applied by both doctors and paramedical workers, even under the most primitive conditions. The scarcity of neurologists among those caring for leprosy patients may have prevented the introduction of some useful methods, but maybe the omitted neurological techniques are believed to contribute so little to diagnosis and to assessment of treatment effects that they are considered to be not worth the trouble. In support of this assumption Sabin and Swift state-but do not document-in their chapter on leprosy, which appears in one of the most authoritative handbooks on peripheral neuropathies, ${ }^{5}$ that vibration sense and position sense are usually spared and that stretch reflexes are preserved.

We had the opportunity to perform an explorative neurological examination of 28 male leprosy patients, admitted to the Anandaban and Green Pastures Hospitals in Nepal. The aim of our investigation was to discover if a slightly more extended neurological examination would be of value in the care and treatment of leprosy patients.

\section{Patients and methods}

The patients were male and between 20 and 50 years old. They suffered from advanced forms of leprosy and had been admitted to hospital for neuritis or ulcer treatment, or for surgical reconstruction. They had undergone a standard examination programme which included 'body charting' to detect skin lesions and anaesthesia, skeletal muscle tests and palpation of peripheral nerves. Standard testing involved manual examination and the assessment of power of a large number of limb muscles according to MRC criteria, and functional tests of facial and hand muscles. Slit-skin smears, lepromin tests and other relevant laboratory tests had been performed in all cases. In these patients we tested: (i) gait; (ii) toe- and heel-walking; (iii) Romberg sign; (iv) tendon reflexes; (v) positional sense; and (vi) pin-prick sensation. Vibration sense was not included because an adequate tuning fork was not available! Examination of gait involved walking to and fro for 5-10 $\mathrm{m}$. When toe- and heel-walking, the patients were encouraged to lift their heels and toes as high as possible. For the Romberg sign, patients were asked to stand with their feet together and their eyes closed for 20-30 s. The examined reflexes were the biceps and triceps reflexes in the upper limbs and the knee and Achilles tendon reflexes in the lower limbs. The ulnar and radius reflexes were not included as these are of ten not present in otherwise normal subjects. ${ }^{6}$ The position sense of $1-5$ digits per limb was examined. Examination of pin-prick sensation was performed with a wooden toothpick to preclude the risk of bleeding. Examination of this sensory modality was restricted to the plantar side of the toes and the volar and/or dorsal sides of the index or middle finger, the little finger and the ulnar sides of the hands and lower arms.

\section{Results}

GAIT, TOE- AND HEEL-WALKING AND THE ROMBERG SIGN

Recent lower limb surgery or ulcer treatment prevented gait examination in 10 cases. Gait was never broad-based and no clear-cut evidence of ataxia was seen; three patients were 
found to have (not or not yet operated) unilateral or bilateral asymmetrical foot drop, confirming the results of previous muscle testing. Toe-walking demonstrated in 1 of these patients a unilateral mild weakness of plantar flexors of the foot which had not previously been discovered, and in another a slight instability of gait and abnormal toe-walking was shown, but the reason for this could not be established with certainty because he had toe deformities as well as a marked disorder of position sense. In this latter case, the Romberg sign (swaying or loss of equilibrium whilst standing with eyes closed) was positive. In 3 other cases, testing of the Romberg sign revealed swaying. In the remaining 14 cases the Romberg sign provoked no swaying.

\section{TENDON REFLEXES (Table 1)}

The tendon reflexes were mostly preserved, both in $\mathrm{BT}$ and in $\mathrm{BL} / \mathrm{LL}$ patients. The Achilles tendon reflex in BT patients was to some extent an exception as it could not be elicited in $40-50 \%$ of the cases. It is remarkable that in 3 cases (2 BT and $1 \mathrm{BL}$ ) tendon reflexes could not be elicited at all. This is compatible with a generalized disorder of the peripheral nerves but is occasionally seen in otherwise normal individuals.

\section{POSITION SENSE (Table 2)}

Position sense of 1 or more digits in 1 or more limbs was abnormal in up to $33 \%$ of the cases. With few exceptions, loss of position sense was asymmetrical and not found simultaneously in toes and fingers. If position sense was affected in 1 digit, other digits of the same limb were often not affected to the same degree or not at all. Loss of position

Table 1. Presence of tendon reflexes in BT, BL/LL, BB and PN patients

\begin{tabular}{|c|c|c|c|c|}
\hline \multirow[b]{2}{*}{ Reflex } & BT $(N=17)$ & $\mathrm{BL} / \mathrm{LL}(N=9)$ & \multirow{2}{*}{$\begin{array}{c}\mathrm{BB}(N=1) \\
n\end{array}$} & \multirow{2}{*}{$\begin{array}{c}\mathrm{PN}\left(\begin{array}{c}N=1) \\
n\end{array}\right.\end{array}$} \\
\hline & $n(\%)$ & $n(\%)$ & & \\
\hline \multicolumn{5}{|l|}{ Biceps } \\
\hline right & $12(71)$ & $8(89)$ & 1 & 1 \\
\hline left & $13(76)$ & $8(89)$ & 1 & 1 \\
\hline \multicolumn{5}{|l|}{ Triceps } \\
\hline right & $11(65)$ & $7(88)^{*}$ & 1 & 1 \\
\hline left & $14(82)$ & $6(75)^{*}$ & 1 & 1 \\
\hline \multicolumn{5}{|l|}{ Knee } \\
\hline right & $12(71)$ & $7(78)$ & 1 & 1 \\
\hline left & $15(88)$ & $7(78)$ & 1 & - \\
\hline \multicolumn{5}{|l|}{ Achilles } \\
\hline right & $7(50) \dagger$ & $6(67)$ & - & 1 \\
\hline left & $9(56) \ddagger$ & $7(78)$ & - & - \\
\hline
\end{tabular}

$N$, number of patients per leprosy type; $n$, number of patients with tendon reflexes; number of patients in whom reflex could be examined: ${ }^{*}, 8 ; \dagger, 14 ; \ddagger, 16$. 
Table 2. Intact position sense in $\mathrm{BT}, \mathrm{BL} / \mathrm{LL}, \mathrm{BB}$ and $\mathrm{PN}$ patients

\begin{tabular}{|c|c|c|c|c|}
\hline \multirow[b]{2}{*}{ Location } & \multirow{2}{*}{$\frac{\mathrm{BT}(N=17)}{n(\%)}$} & \multirow{2}{*}{$\frac{\mathrm{BL} / \mathrm{LL}(N=9)}{n(\%)}$} & \multirow{2}{*}{$\begin{array}{c}\mathrm{BB}(N=1) \\
n\end{array}$} & \multirow{2}{*}{$\begin{array}{c}\mathrm{PN}(N=1) \\
n\end{array}$} \\
\hline & & & & \\
\hline \multicolumn{5}{|l|}{ Fingers } \\
\hline right & $10(67)^{*}$ & $8(89)$ & 0 & 1 \\
\hline left & $12(71)$ & $9(100)$ & 0 & 1 \\
\hline \multicolumn{5}{|l|}{ Toes } \\
\hline right & $8(67) \dagger$ & $7(78)$ & 0 & 1 \\
\hline left & $14(88) \ddagger$ & $6(67)$ & 0 & - \\
\hline
\end{tabular}

$N$, number of patients per leprosy type; $n$, number of patients with intact position sense; number of patients in whom position sense could be examined: *, 15; †, 12; $\ddagger 16$.

sense reflects dysfunction of thick sensory nerve fibres innervating muscle spindles (A $\alpha$ fibres, $13-30 \mu \mathrm{m}$ in diameter) and Golgi tendon organs located in muscle tendons (A $\beta$ fibres, 6-12 $\mu \mathrm{m}){ }^{7}$ As Romberg $\operatorname{sign}^{7}$ and tendon reflexes ${ }^{8}$ are equally dependent on functioning of thick sensory nerve fibres (innervating muscle spindles), it was considered interesting to compare the results of these examinations with those of position sense (Table 3). Approximately $50 \%$ of the patients in whom evidence of a disorder of thick sensory nerve fibres was found on examination of (Achilles) tendon reflexes and position sense showed an abnormality of the Romberg sign. When the Romberg sign was considered to be abnormal, tendon reflexes ( 1 case) or tendon reflexes and position sense (3 cases) were also abnormal.

\section{PIN-PRICK SENSATION}

Pin-prick sensation was not abnormal in the examined digits of four cases ( $3 \mathrm{LL}, 1 \mathrm{BT}$ ) and could not fully be examined in 2 (BT) cases. In all other cases pin-prick sensation was abnormal in 1 or more digits of 1 or more limbs. This result confirms that of the previously performed standard examination of pressure sensation, but it should especially be noted that in patients who are used to walking barefoot, callous formation is of ten heavy, and in such cases, pressure examination of the soles of the feet may erroneously lead to a

Table 3. Relationship between Romberg sign and position sense/tendon reflexes of the lower limbs

\begin{tabular}{lcc}
\hline & \multicolumn{2}{c}{ Romberg sign } \\
\cline { 2 - 3 } Position sense/reflexes & Normal & Abnormal \\
\hline Normal & 11 & 0 \\
Abnormal & 3 & 4 \\
\hline
\end{tabular}


conclusion of anaesthesia instead of hypaesthesia. We saw patients who were considered to have anaesthetic soles, but who still felt some pain.

\section{Discussion}

The neurological manifestations of leprosy are highly characteristic. Hypaesthetic, hypopigmented skin lesions are not likely to be seen in other diseases and in leprosy the decrease in cutaneous sensation related to skin temperature is unique. ${ }^{5}$ Facial muscle weakness usually presents as lagophthalmus, whereas in most other facial nerve disorders, the weakness of peri-oral muscles predominates or is at least not less pronounced than the weakness of peri-orbital muscles. Palpable thickening of peripheral nerves is common in leprosy. It may be found, locally, in some cases of entrapment neuropathy, ${ }^{9}$ but is otherwise rarely seen. It occurs in a minority of the patients with hereditary (autosomal dominant) motor and sensory neuropathy type I (HMSN type I or Charcot Marie Tooth disease) and in cases of (autosomal recessive) HMSN type III (Déjerine Sottas disease) which is a very rare disorder. ${ }^{10}$ Refsum disease, which is even more rare, is reported to lead in some cases to palpable peripheral nerve thickening, ${ }^{11}$ but this is not confirmed by other authors. $^{12}$ Polyneuropathy with palpable thickening of peripheral nerves and foot ulceration has been described as an exceedingly rare manifestation of neurofibromatosus. ${ }^{13}$ Plexiform neurofibromas in patients suffering from neurofibromatosus are usually associated with typical skin lesions, which allows easy differentiation from leprosy. ${ }^{14}$ In amyloid neuropathy, nerves may be thickened, but the suggestion in some textbooks on leprosy ${ }^{1,2}$ that palpable nerve thickening is a clinical feature of familial or primary amyloid neuropathy is erroneous. ${ }^{15,16}$ This all supports the view that the differentiation of leprosy neuropathy from other neuropathies will usually be quite straightforward. It may only prove problematic in some pure neuritic cases without peripheral nerve thickening.

The findings of this study suggest that: (i) position sense may be affected asymmetrically in 1 or more digits of 1 or more limbs, compatible with local pathology in 1 or several peripheral nerves, as in mononeuritis multiplex; (ii) changes in cutaneous sensibility are commonly well covered by current methods for investigation of pressure sensation; (iii) tendon reflexes are usually but not always preserved; and (iv) evidence for diffuse changes of thick sensory nerve fibres in the lower limbs leading to sensory ataxia is slight and usually lacking. These results fit nicely with the concept of leprosy neuropathy being a mononeuritis multiplex - with the exception of far-advanced cases of LL leprosy. On their own, they do not allow the distinction of leprosy neuropathy from other causes of mononeuritis multiplex and therefore are not helpful in the differential diagnosis of pure neuritic cases. They do demonstrate, however, that changes of position sense and of Achilles tendon reflexes are not exceptional.

The value of grading muscle strength according to the MRC scale is currently under discussion. ${ }^{17}$ We agree with Fritschi that functional tests are easy to perform and highly informative. ${ }^{18}$ They are therefore particularly useful in field conditions. For assessment of the effects of therapy, as for example by corticosteroids in neuritic patients, a myometer is to be preferred to manual testing as it is more accurate. ${ }^{19-22}$ The present investigation included 2 simple functional tests: toe- and heel-walking. Heel-walking confirmed what was already known from manual investigation. Toe-walking requires lifting the weight of the whole body against gravity and is therefore a much more sensitive test for triceps surae 
muscle weakness than manual testing. Weakness of the $\mathrm{m}$. triceps surae reduces stability when standing and leads to a flat-foot gait. In this investigation, toe-walking revealed mild weakness of the triceps surae muscle in 1 limb of 1 case. Weakness of the triceps surae muscle is not generally considered to be a feature of leprosy, but has previously been reported in 7 of $25 \mathrm{LL}$ patients. ${ }^{23}$

Loss of position sense of the fingers reflects a severe impairment of the distal, thick sensory nerves. It has an adverse effect on manual dexterity and hinders rehabilitation. This study shows that loss of position sense of the fingers occurs frequently in advanced forms of leprosy. Proper case management should therefore include prevention and/or improvement of this defect.

We could not investigate if the examination of pain sensation might facilitate the early diagnosis of leprosy. Our results indicated, however, that for proper case management, it may be useful to examine the pain sense in areas where patients are liable to develop ulcers. Loss of pain sensation and unperceived traumata are generally held to be responsible for the occurrence of ulcers. ${ }^{9}$ Examination by pin-prick revealed residual pain sensation in some of the feet that were considered to be anaesthetic. It is our experience in patients with hereditary sensory neuropathy that prognosis, when foot ulcers recur, is better when slight pain sensation is preserved than when it is totally absent.

In conclusion: (a) in diagnosis, no grounds were found to advocate a more extensive neurological examination than is customary; and (b) a full neurological examination may, however, be relevant for case management as it assesses in greater detail the extent of damage to the peripheral nervous system. It is suggested that quantification of muscle strength by means of a myometer may be of value for the assessment of effects of therapy.

\section{Acknowledgments}

We are grateful to the medical superintendents Drs W Theuvenet of the Anandaban Hospital and W van Brakel of the Green Pastures Hospital for their permission to examine patients under their care and to Mrs No Bu Ko for translating instructions and responses.

\section{References}

1 Hastings RC. Leprosy. Medicine in the tropics series. Churchill Livingstone, Edinburgh, 1985; pp. 137-140.

2 Bryceson A, Pfaltzgraff RE. Leprosy. Medicine in the tropics series. Churchill Livingstone, Edinburgh, 3rd ed, 1990; pp. 57-60.

3 Ganapati R, Revankar CR. Clinical aspects of leprosy. In: The biology of the mycobacteria. Ratledge C, Stanford J, Grange JM (eds). Academic Press, London, 1989; pp. 328-58.

4 Semmes J, Weinstein S, Ghent L, Teuber H-L. Somatosensory changes after penetrating brain injury in man. Harvard University Press, Cambridge, 1960.

5 Sabin TD, Swift TR. Leprosy. In: Peripheral Neuropathy, volume 2. Dyck PJ, Thomas PK, Lambert EH, Bunge R (eds), 2nd ed, Saunders, Philadelphia, 1984; pp. 1955-87.

${ }^{6}$ Stan J, Van Crevel H. Measurement of tendon reflexes by surface electromyography in normal subjects. J Neurol, 1989; 236: 231-7.

7 Martin JH. Receptor physiology and submodality coding in the somatic sensory system. In: Principles of neural science. Kandel ER, Schwartz JH (eds). Elsevier, New York, 2nd ed, 1985; pp. 287-300.

8 Carew TJ. The control of reflex action. In: Principles of neural science. Kandel ER, Schwartz JH (eds). Elsevier, New York, 2nd ed, 1985, pp. 457-68.

9 Thomas PK. Symptomatology and differential diagnosis of peripheral neuropathy: clinical features and 
differential diagnosis. In: Peripheral neuropathy, volume 2. Dyck PJ, Thomas PK, Lambert EH, Bunge R (eds), Saunders, Philadelphia, 2nd ed, 1984, pp. 1169-90.

10 Ouvrier PA, McLeod JG, Conchin TE. The hypertrophic Charcot Marie Tooth disease (HMSN type I) and Déjerine Sottas disease (HMSN type III) in childhood. Brain, 1987; 110: 121-48.

11 Refsum S. Clinical and genetic aspects of Refsum disease. In: Peripheral Neuropathy, volume 2, Dyck PJ, Thomas PK, Lambert EH, Bunge R (eds), Saunders, Philadelphia, 2nd ed, 1984, pp. 1866-98.

12 Jennekens FGI. Hereditary atactica pol yneuritiformis (Refsum disease). In: Handbook of Clinical Neurology, revised series, volume 7. Vinken PH, Bruyn GW, Klawans HL (eds), Elsevier, Amsterdam, 1987, pp. 384-5.

13 Thomas PK, King RHM, Chiang TR, Scaravilli F, Sharma AK, Downie AW. Neurofibromatous neuropathy. Muscle Nerve, 1990; 13: 93-101.

14 Riccardi VM, Eichner JE. Neurofibromatosus: phenotype, natural history and pathogenesis. Johns Hopkins University Press, Baltimore, 1986: pp. 38-51.

15 Cohen AS, Rubinow A. Amyloid neuropathy. In: Peripheral Neuropathy, volume 2. Dyck PJ, Thomas PK, Lambert EH, Bunge R (eds), Saunders, Philadelphia, 2nd ed, 1984, pp. 1866-98.

16 Kelly JJ. Amyloidosis. In: Polyneuropathies associated with plasma cell dyscrasias. Kelly JJ jr, Kyle RA, Latow N (eds), Nyhoff, Boston, 1987: pp. 105-27.

17 Cook JD, Glass DS. Strength evaluation in neuromuscular disease. Neurologic Clinics, 1987; 5: 101-23.

18 Fritschi EP. Field detection of early neuritis in leprosy. Lepr Rev, 1987; 58: 173-7.

19 Wiles CM, Karni Y. The measurement of muscle strength in patients with peripheral neuromuscular disorders. J Neurol Neurosurg Psychiat, 1983; 46: 1006-13.

20 Van der Ploeg RJO, Fidler V, Oosterhuis HJGH. Hand-held myometry: reference values. J Neurol Neurosurg Psychiat, 1991; 54: 244-47.

${ }^{21}$ Van der Ploeg RJO, Oosterhuis HJGH. The 'make/break test' as a diagnostic tool in functional weakness. J Neurol Neurosurg Psychiat, 1991; 54: 248-51.

22 Hosking, GP, Bhat US, Dubowitz V, Edwards RHT. Measurement of muscle strength and performance in children with normal and diseased muscle. Arch Dis Child, 1976; 51: 957-63.

${ }^{23}$ Swift TR, Hackett ER, Shipley DE, Miner KM. The peroneal and tibial nerves in lepromatous leprosy. Clinical and electrophysiologic observations. Int J Lepr, 1973; 41: 25-34. 


\title{
Examen neurologique des patients souffrant de la lèpre: est-il justifié
}

\author{
F G I Jennekens et A Jennekens-Schinkel
}

Résumé Nous avons examiné 28 lépreux males pour découvrir si un examen neurologique plus extensif que l'habituel serait justifié pour le diagnostic de la maladie et sa direction. Nos résultats sont tout à fait compatibles avec ceux que l'on attendrait d'une mononévrite multiple, due soit à la lèpre soit à d'autres causes. Les observations suivantes méritent d'être notées: Des changements de la sensation de la position et une diminution de certains reflexes tendineux étaient présents chez une minorité des patients. Sur les plantes des pieds considérées comme anaesthésique ou hypoesthésiques, on pouvait parfois déceler un reste de sensation de douleur. Le test du fonctionnement d'au moins un groupe de muscles (muscle triceps sural) s'est révélé plus fiable que le test manuel selon les critères MRC. Nous avons conclu qu'un examen neurologique extensif n'est probablement pas necessaire pour le diagnostic. Il fournit, pourtant, une information plus précise sur l'éstendue de l'atteinte du système nerveux périphérique, ce qui peut être important pour la conduite et l'évaluation des effets du traitement. L'utilisation d'un myomètre est recommandé.

\section{El estudio neurologico de los pacientes leprosos; ¿vale la pena?}

\section{F G I JENNEKENS Y A JENNEKENS-SCHINKEL}

Resumen Hemos examinado 28 hombres pacientes leprosos para establecer si valdría la pena hacer una investigación neurológica más extensa que la normal, para el diagnóstico y/o el tratamiento. Los resultados que obtuvimos eran totalmente compatibles con lo que se anticiparía de una mononeuritis multiplex, debida a la lepra u otras causas. Se destacan las siguientes observaciones. Se presentaron cambios del sentido posicional y una reduccíon de algunos de los reflejos de los tend ones en una minoría de los pacientes. En las plantas de los pies que se consideraban an- o hipo-anestéiscos, se podía detectar ocasionalmente una sensación de dolor residual. Pruebas funcionales de la menos un grupo de músculos ( $\mathrm{m}$. triceps suræ) parecían ser más fiables que las pruebas manuales, según los criterios MRC. Hemos concluido que probablemente no es necesario un extenso estudio neurológico para el diagnóstico. Sin embargo, éste proporciona información más precisa sobre el alcance del daño al sistema nervioso periférico que puede ser importante desde el punto de vista del tratamiento y de la evaluación de los efectos que ha tenido. Se favorece el uso de un miómetro. 